\title{
O PRÉ-ESCOLAR DE DOIS A SEIS ANOS DE IDADE E O SEU ATENDIMENTO
}

Yaro Ribeiro Gandra *

GANDRA, Y. R. O pré-escolar de dois a seis anos de idade e o seu atendimento.

Rev. Saúde públ., S. Paulo, 15(supl.):3-8, 1981.

RESUMO: E evidenciada a importância da fase pré-escolar de 2 a 6 anos, tanto no que diz respeito ao processo de maturação biológica como ao desenvolvimento sócio-psicomotor por que passa a criança em seu relacionamento com o meio ambiente. Este importante grupo etário é um dos mais carentes de atendimento no país, estimando-se que mais de $90 \%$ deles não consegue cbter nenhuma orientação ou assistência formal. Sugerese a adoção de alternativas menos sofisticadas conforme o Progama de Educação e Alimentação do Pré-Escolar, este, mais compatível com as infra-estruturas e recursos existentes no país. Este programa se propõe proporcionar, em caráter conjuntural e supletivo, o atendimento integral, abrangente e de baixo custo aos pré-escolares. CEAPE.

UNITERMos: Pré-escolares, nutrição. Criança, assistência. Programa

\section{INTRODUÇAO}

Os pré-escolares de 2 a 6 anos de idade constituem faixa populacional de grande importância, quer devido ao processo de maturação biológica por que passam, durante o qual a alimentação desempenha papel decisivo, quer pelo desenvolvimento sócio-psicomotor, para o qual contribuem fundamentalmente os meios familiar e comunitário em que vivem e, complementarmente, as instituições que os assistem.

o primeiro processo é o da formação, quando os tecidos se organizam e as funços celulares e tissulares se definem por me1o de substituições que decorrem de atividades fisio-metabólicas destinadas a manter, em funcionamento, todo o complexo bio-orgânico do indivíduo. Para conseguir tal desiderato, entretanto, deve o pré-escolar contar com sistema regular de abastecimento de nutrientes capaz de propiciar seu pleno desenvolvimento. Relembra-se que aos 2 anus de idade o peso da criança já é o quádruplo daquele do nascimento, aumentando, cn continuação, cerca de dois quilos por año de idade. Aos 6 anos já pesa cerca de se!s vezes mais e o seu perímetro craniano atinge a nove décimos de seu valor adulto. Quando o pré-escolar chega aos 4 anos, já possui cerca de $90 \%$ da massa cerebral do adulto. Esta é, portanto, uma fase de rápido desenvolvimento anátomo-fisiológico para a qual a nutrição tem importância fundamental.

Paralelamente ao desenvolvimento anátomo-fisiológico, a criança necessita receber do meio ambiente estimulos e solicitações

\footnotetext{
* Do Departamento de Nutrição da Faculdade de Saúde Pública da USP - Av. Dr. Arnaldo, 715 - 01255 - São Paulo, SP - Brasil.
} 
GANDRA, Y. R. O pré-escolar de dois a seis aros de idade e o seu atendimento. Rev. Saúde públ., S. Paulo, 15(supl.): 3-8, 1981.

adequados para que desenvolva suas estruturas cognitivas por meio de processo espontâneo e de interação com o meio em que vive. Este desenvolvimento psicossocial e cognitivo da infância desempenha importante papel no futuro comportamental do individuo na comunidade biótica em que vai viver. $O$ acervo de conhecimentos adquiridos é progressivo, cumulativo e sua aquisição obedece a norma seqüencial e a um rítmo que é determinado pela densidade e qualidade dos estímulos recebidos.

Toda criança possui uma base informacional que a torna apta a receber as informações biológicas: genéticas ou neuronais. As primeiras constituem "o plano básico de construção do indivíduo" e que, de certo modo, predispóem ou pré-determinam o seu comportamento frente aos estímulos que receberá.

A par uas informações genéticas, o individuo também traz ou recebe informações ao nivel neuronal (informações neuronais programadas e programáveis). O cérebro contém cerca de dez bilhóes de neurônios e, como cada neurônio tem de mil a dez mil sinapses, conta o ser humano, na realidade, com dez a cem trilhões de sinapses programáveis. Percebe-se, por aí, a alta habilidade que tem o homem em armazenar informações em nivel neuronal, uma vez que dispõe de maior número de neurônios programáveis que os demais animais.

As "informaçōes neuronais programadas" já são parte do individuo por ocasião do seu nascimento. É o que explica, por exemplo, $o$ instinto e os reflexos neuro-musculares e respiratórios, do ato de mamar e tantos outros. Estas informações neuronais, já programadas, possibilitam, na realidade, a fase inicial de acomodação do ser vivo na sua interface $\mathrm{com}$ o meio ambiente.

Os neurônios possuem também capacidade aberta para incorporarem novas informações recebidas após o nascimento (informações neuronais programáveis). Esta incorporação iră depender do grau de interação do indj- viduo com o meio em que vive. Há, na realidade, um número muito grande de neurônios livres aptos a gravarem informações não-genéticas e estocá-las em sua organização estrutural. O cérebro processa, através das sinapses neuronais, cerca de cinco mil conjuntos de sinais por segundo. Essas sinapses, que transferem tensões ou cargas elétricas, comportam-se semelhantemente aos circuitos electrônicos podendo ser abertas ou fechadas conforme os fluxos de informações. Há, portanto, à disposição do indivíduo, um grande acervo anátomo-funcional qualificado para receber informações do meio ambiente do qual o indivíduo dependerá para formar o seu acervo cognitivo.

Ademais dessas informações adquiridas pelos neurônios, poderiamos lembrar glue ainda existem outras extra-somáticas que se processam através de simbolos criados pelo próprio homem que, desta forma, poderá guardar informações fora dos próprios neurônios. As informações extra-somáticas aumentam significantemente a capacidade informacional do homem.

É de se ver que a massa de informaçōes neuronais programáveis, embora tenha sua base na herança biológica, vai depender, evidentemente, dos estímulos que a criança recebe do meio em que vive.

O relacionamento com o meio propicia como um todo, acúmulo concatenado de conhecimentos e habilidades novos, adquiridos através da linguagem, da atividade motora, do inter-relacionamento social e da aprendizagem.

O processo do conhecimento é, na realidade, $o$ resultado do relacionamento do sujeito com o evento, com o fato, com o objeto que o meio se lhe apresenta, resultando daí a aquisição de uma representação intelectual daquele evento ou objeto, que em seguida passa a pertencer ao seu acervo próprio.

As sucessivas interaçōes que ocorrem somam-se umas às outras para constituirem 
GANDRA. Y. R. O pré-escolar de dois a seis aros de idade e o seu atendimento. Rer: Saíde publ., S. Paulo. 15(supl.): 3-8, 1981.

o "processo cognitivo". A "aquisição" desses conhecimentos é conseguida através do que st chama de processo de adaptação que nada mais é que o resultado do equilibrio harmônico da criança com o meio em que vive. A adaptação é conseguida através da "assimilaçāo" e da "acomodação". A primeira se processa quando o organismo modifica o objeto ou o fato externo para melhor incorporá-lo às suas estruturas cognitivas em formação, e a segunda, quando o próprio organismo se modifica no sentido de acomodar-se à nova situação. Esses processos vāo constituir a base do desenvolvimento da criança sem contudo atritarem as estruturas pré-formadas. Quanto maior o contingente assimilado e acomodado maior será a capacidade de assimilação e de acomodação a novos contingentes. As operaçōes cognitivas dāo os alicerces para o raciocínio da criança e, como diz Piaget, nada mais são que "uma reconstruçāo endógena de dados exógenos fornecidos pela experiência".

O processo de aprendizagem posterior utiliza o sistema de estruturas pré-formadas com o desenvolvimento; de onde se conclui que ele depende deste mesmo desenvolvimento. A aprendizagem por si mesma não dá origem a novas estruturas embora possa modificá-las em sua interação\%. A inteligência, que também pressupõe una estrutura preestabelecida, não dispensa um processo de troca com o meio. Este a exercita e potencializa progressivamente através de novas experiências da criança com o mundo externo em que vive. É a capacidade de se equacionar, frente a novas experiências, os conhecimentos incorporados em experiências anteriores.

O desenvolvimento da criança nesse aspecto foi profundamente estudado por Piaget e suas lições clássicas permanecem até hoje como diretrizes que têm servido de base às pesquisas posteriores nesta área.

Sabe-se que o desenvolvimento da criança se processa por etapas cuja instalação obedece a uma certa ordem seqüencial idêntica para todos os individuos. Esta sequiência tem caráter somatório.

Por outro lado, existe um ritmo nesta ordenação, rítmo este variável de acordo com a densidade de estimulações que 0 ambiente oferece. Quanto mais frequentes, quanto mais adequadas forem estas estimulaçôes, mais acelerado será o ritmo do desenvolvimento. Pré-escolares que cresceram em ambientes carentes de estimulos não apresentam facilidade para a aprendizagem uma vez que não possuem estruturas operacionais aptas a equacionarem novos eventos e seqüências.

Daí se compreender a importância do atendimento ao pré-escolar nessa fase de desenvolvimento, no sentido de complementar os estímulos que a criança recebe do meio familiar e comunitário em que vive. As crianças que advêm de meios menos favorecidos apresentam, por exemplo, um vocabulário pobre além de não possuirem agilidade lingüistica suficiente para manifestarem seu pensamento ou sua rontade. $O$ s vocábulos simples sāo complementados por gestos na ausência de maior facilidade lingüistica. Essas crianças apresentam um código de linguagem bastante diferente das de classe media ou alta; os próprios vocábulos muitas vezes têm significados diferentes e muitos deles são inteiramente desconhecidos pois não estão presentes nos diálogos que ocorrem em seus próprios lares. Quanto mais estimulante for 0 ambiente, mais rapidamente se desenvolve a capacidade intelectual da criança.

O educador, o orientador, portanto, têm que providenciar aos pré-escolares, mais que o ensino, os procedimentos adequados que garantam o desenvolvimento integral da criança. Esses procedimentos devem ativar as estruturas pré-operacionais a fim de que o exercicio permanente da razão permita tornar suas estruturas verdadeiramente opsracionais.

Neste processo, em que as experiências se somam, fácil é pois reconhecer a importância da fase pré-escolar no processo erolu- 
GANDRA, Y. R. O pré-escolar de dois a seis anos de idade e o seu atendimento. Ren. Saúde públ., S. Paulo, 15(supl.): 3-8, 1981.

tivo da criança. Aquelas que coabitam lares pobres, plenos de privações, carentes de estímulos, de diálogos, não têm as mesmas chances para se desenvolverem que aquelas das classes mais privilegiadas; sua cognição é modesta, seu vocabulário é limitado, sua sociabilidade incipiente e sua atividade não encontra eco. É a privação cultural.

Essas crianças, ao atingirem a jdade escolar, entram nessa estrutura de ensino sem as condições mínimas para acompanharem o currículo escolar do $1^{\prime \prime}$ grau, curriculo este organizado para as classes média e alta do país.

Considerando que das crianças matriculadas na primeira série do 1" grau, mais de $60 \%$ provém de famílias de baixo nível sócio-econômico, e que essas crianças são portadoras de carências alimentares e culturais que condicionam atraso no seu desenvolvimento físico e mental de, em média, dois anos, impõe-se a busca de soluções formais, institucionalizadas, e também não formais, conjunturais, para se ampliar o atendimento ao pré-escolar como meio, inclusive, de aumentar a rentabilidade do ensino do 1 \% grau.

Os pré-escolares do Brasil constituem o grupo populacional mais carente de atendimento, embora represente uma parcela importante na estrutura etária do país.

De acordo com as estimativas do Ministério de Educação e Cultura (MEC)i, o Brasil contava em 1978 com 21.000 .000 crianças pré-escolares. E destas, cerca de 17.000.000 na faixa etária de 2 a 7 anos de idade. Deste contigente, apenas 600.000 pré-escolares eram atendidos por instituiçōes especializadas. Em que pese a imprecisão das estatisticas oferecidas pelos órgãos oficiais, pode-se estimar que não mais do que $5 \%$ dos pré-escolares de 2 a 6 anos de idade são atendidos por instituições oficiais ou particulares do Brasil.

Vários serviços, tais como creches, parques infantis, escola de educação pré- escolar e outras, atendem no país ao pré-escolar. Entretanto, o que se pode concluir é que as instituições, embora persigam os seus objetivos iniciais, não conseguem atender a fração significativa da população pré-escolar, pois que $95 \%$ dos pré-escolares nessa faixa etária não recebem nenhum atendimento complementar que assista ao seu desenvolvimento. Deve-se notar ainda que a maioria ( $51 \%$ ) das classes pré-escolares no Brasil, é de iniciativa particular e, portanto, não se destinam ao atendimento das classes de nivel sócio-econômico mais baixo, isto é, as que mais necessitam de assistência 1 .

De alguns anos para cá as autoridades nacionais relacionadas com a educação vêm desenvolvendo esforço no sentido de aumentar a oportunidade do pré-escolar se engajar no sistema de atendimento. $O$ número de matrículas de pré-escolar vem aumentando gradativamente. $\mathrm{O}$ rítmo anual de aumento de matrículas em relação a população pré-escolar está em torno de $0,25 \%$ e, nestas condições, para que se atinja, por exemplo, $70 \%$ dos pré-escolares existentes no Brasil, levar-se-ia cerca de 260 anos.

Tendo em vista que $o$ atendimento global - precoce ao pré-escolar repercute, favoravelmente, sobre o rendimento pedagógico 7 e sobre os custos do sistema educacional, minimizando a elevada taxa de repetência nas primeiras séries do lo grau e a acentuada evasão e o absenteísmo escolar .. 
GANDRA, Y. R. O pré-escolar de dois a seis anos de idade e o seu atendimento. Rev. Sańde públ., S. Paulo, 15(supl.): 3-8, 1981.

considerando os recursos disponiveis para a ampliação deste atendimento - impunha-se desde lcgo a busca de soluções complementares compativeis com a realidade nacional e que, embora não satisfazendo todas as exigências pedagógicas instituidas no pais, propiciariam maior cobertura oferecendo à criança, na época certa, a oportunidade de acelerar o seu desenvolvimento integral.

E 1972, o Departamento de Nutrição da Faculdade de Saúde Pública da USP planejou o programa CEAPE (Centro de Educação e Alimentação do Pré-Escolar) ${ }^{3.4}$ de baixo custo, capaz de ampliar o atendimento aos pré-escolares, uma vez que é compativel com a infra-estrutura e recursos existentes no país. Este programa tem como objetivo dar atendimento integral aos pré-escolares, principalmente àqueles das populações de baixa renda, fornecendo-lhes suplementação alimentar ao mesmo tempo que um programa específico de recreação orientada com o propósito de estimular o desenvolvimento físico, psicomotor, intelectual, social e emocional dessas crianças. Este programa inclui a participação ativa da mãe do pré-escolar e utiliza, ao máximo, os recursos preexistentes na comunidade. Todo programa CEAPE conta com um sistema testado de avaliação de eficiência e de eficácia.

Sistemas menos sofisticados, como 0 CEAPE, por serem mais econômicos, poderão garantir maior cobertura assistencial aos pré-escolares. Muitos programas que seguem a filosofia e a metodologia do CEAPE estão sendo implantados em vários pontos do território nacional. São programas que oferecem, além da suplementação alimentar, um ambiente estimulante que propicia à criança oportunidade para organizar seu próprio sistema de pensamento e manifestar suas idéias através de um vocabulário progressivamente desenvolvido.

Considerando-se que o programa CEAPE, implantado e avaliado, mostrou-se eficiente e eficaz, concluimse pela oportunidade e pertinência da implantação de programas com esta filosofia que, sem prejudicar 0 desenvolvimento dos programas convencionais, proporcionarão em caráter conjuntural e supletivo, o atendimento integral, abrangente e de baixo custo aos pré-escolares do país.

GANDRA, Y. R. [The preschool child of 2 to 6 years of age and the assistance given him]. Rev. Saúde públ., S. Paulo, 15(suppl.):3-8, 1981.

ABSTRACT: The importance of the preschool phase (from 2 to 6 years of age) in children is emphasised, with regard to the biological maturation process as well as to socio-psycho-motor development which occurs in this phase as a consequence of environmental stimuli. However this important age group is barely reached by the various existing programs and receives the least nutritional assistance and socio-cultural guidance. In Brazil more than $90 \%$ of this group receive no kind of organized assistance. An alternative, less sophisticated, program is suggested, on Preschool Education and Feeding Centre (CEAPE) lines, more consistent with local resources. This type of program recommended provides all-round assistance to this very import age group, at low cost.

UNITERMS: Child, preschool. Nutrition. Child care. CEAPE Program. 
GANDRA, Y. R. O pré-escolar de dois a seis anos de idade e o seu atendimento. Rev. Saúde públ., S. Paulo, 15(supl.): 3-8, 1981.

\section{REFERENCIAS EIBLIOGRAFICAS}

1. ANUARIO ESTATISTICO DO BRASIL. (Fundação IBGE). Rio de Janeiro, 1978. p. 242 .

2. ASSIS, O.Z.M. Uma nova metodologia $e$ educação pré-escolar. São Paulo, Pioneira, 1979.

3. GANDRA, Y.R. Asistencia alimentaria por médio de centros de educación y alimentacion del pre-escolar. Bol. Ofic. sanit. panamer., 74:302-14, 1973.

4. GANDRA, Y.R. Nutrition and dietetic education program for pre-school children at primary schools in Brazil. In: Anderson, M.A. \& Grewal, T.. ed. Nutrition planning in developing world: proceedings of Regional Workshops held by
CARE in India, Kenya and Colombia, 1976. Bogotá, Programas Editoriales. 1976. p. $205-12$

5. MINISTERIO DE EDUCAÇAO E CULTURA. Atendimento ao pré-escolar. Brasília, 1977. v. 1.

6. PIAGET, J. Psicologia da inteligência. Rio de Janeiro, Zahar Editores, 1977.

7. POPPOVIC, A.M. et al. Marginalização cultural: subsidios para um curriculo pré-escolar. Cad. Pesq. Fund. Carlos Chagas, 14:7-38, 1975.

Recebido para publicação em 10/07/1981 Aprovado para publicasão em 17/11/1981 